\title{
GINKGO AND THE MICROSPORANGIAL MECHANISMS OF THE SEED PLANTS*
}

\author{
EDWARD C. JEFFREY AND R. E. TORREY
}

(WITH PLATES VII-IX)

The genus Ginkgo has long excited interest as the sole survivor of a group which was formerly numerously represented by species and widely distributed geographically. It is the purpose of the present article to show that its microsporangial structures have an important significance from the standpoint of the interpretation of microsporangia of seed plants in general. It will further be indicated in the present investigation that the affinities of the Ginkgoales are not with the Cycadales, as is ordinarily assumed, but with the abietineous subtribe of conifers, which one of us, in numerous articles devoted to the anatomical structure of living and fossil conifers, has attempted to show are the most primitive living representatives of the coniferous stock. Two important memoirs dealing with the genus under discussion have appeared in recent years. SEWARD and GOWAN ${ }^{\mathrm{r}}$ have given an interesting account of the living Ginkgo, together with statements in regard to its extinct predecessors and its botanical affinities. More recently SPRECHER ${ }^{2}$ has published an admirable description of the anatomical structures of the various vegetative and reproductive organs in the genus.

The microsporophylls of Ginkgo are paired structures opening by means of a stomium along their inner faces. The opening mechanism is a jacket of cells, generally nucleated, with fibrous thickenings extending from the cavity of the mature sporangium to the epidermis. These thickenings are a structural feature of the mechanical layer, and are quite absent in the epidermal layer itself.

* Contribution from the laboratories of Plant Morphology of Harvard University.

${ }^{x}$ Seward, A. C., and Gowan, J., The maiden hair tree (Ginkgo biloba L.). Ann. Botany 14:I09-I54. pls. 8-IO. I900.

${ }^{2}$ Sprecher, Andreas, Le Ginkgo biloba L. 8vo. pp. 208. figs. 205. Geneva. 1907.

$28 \mathrm{x}]$

[Botanical Gazette, vol. 62 
The general distribution and topography of the mechanical tissues of the sporangium may be learned from the somewhat diagrammatic illustration appearing as fig. I7. This figure will be discussed more fully at a later stage. The anatomical details of organization of the microsporangium of Ginkgo, as illustrated by photomicrographs, may conveniently be taken up here. Fig. I shows a vertical section through one of the microsporangia. At the lower side are spores lying within the sporangial cavity. Transversely in the upper region of the figure runs the termination of one of the fibrovascular bundles of the sporophyll. The bundle is accompanied on its upper side by short transfusion cells, such as are characteristic of the gymnosperms. These appear as reticulated elements. To the right and separated from the transfusion tissue by two elongated unsculptured cells is the bundle proper, with its protoxylem elements uppermost and the larger elements of the metaxylem beneath. Toward the left the bundle as a whole ends in transfusion elements, a situation often present in the gymnosperms. The transfusion cells commonly become imperceptibly merged into the fibrously thickened cells which constitute the mechanical tissues of the sporangium wall. Fig. 2 presents another and less favorable view of the same features.

Fig. 3 reproduces a horizontal section through the petiole of the sporophyll and the two sporangia. Right and left lie groups of spores indicating the position of the spore sacs, while in the center is a fan-shaped mass of tracheids marking the termination of the fibrovascular strands of the sporophyll in a complex of transfusion tracheids. To the right and left of the fan lie cells with elongated nuclei, which mark the position of the two strands of phloem ending in the bases of the sporangial cavities. Fig. 4 reproduces a portion of the right of fig. 3, more highly magnified. The gradual passage of the transfusion elements into the cells which constitute the mechanical system of the sporangium wall can now easily be distinguished. To the extreme right are spores in the cavity of the sporangium, and below these, to the right of the transfusion cells, are to be seen two elongated nuclei belonging to the phloem. Returning now to the radial longitudinal view of the vascular supply of the sporangium, in fig. 5 we see under a somewhat high degree 
of magnification transfusion elements above tracheids, which are in turn in intimate contact below with the fibrously thickened mechanical elements of the sporangium. Fig. 6 shows still another view of the tracheids, transfusion and mechanical elements demonstrating their continuity with one another at the termination of the bundle. Below lies a group of spores. Fig. 7 further illustrates, under a considerable degree of magnification, the almost imperceptible transition from the tracheary and transfusion elements of the fibrovascular bundle proper to the reticulated cells which constitute the opening mechanism of the sporangium. To the right in the median horizontal line lie two narrow tracheids. Above and also to the left of these are to be seen transfusion cells with reticulated walls of the type characteristic of Ginkgo and certain Abietineae. Inferiorly the tracheids abut immediately upon the reticulated elements of the mechanical or fibrous layer.

Fig. 8 represents the vascular system of the microsporophyll in transverse section. Sporangia lie to the right and left with contained spores. The two vascular strands which are present in the terminal portion of the sporophyll of Ginkgo end as such at the base of the sporangia. Directly above the sporangial cavities on either hand are masses of small cells, which constitute the phloem of the vascular bundles. The position of the xylem is less apparent and is marked by crosses lying inside the islands of phloem. As the vicinity of the sporangia is reached the fibrovascular strands turn outward, so that the phloem now lies external to the xylem instead of below it, as in the lower region of the sporophyll. In the median region a large amount of mechanical tissue is present, separating the sporangia and continuous with the ends and sides of the xylem of the strands. Fig. 9 represents a more highly magnified and somewhat oblique view of the situation illustrated in fig. 8. To the right may be seen the small elements of the protoxylem of the bundle of the dextral sporangium. On the left the sinstral strand of xylem is obliquely cut, showing pits and reticulations. Farther to the left it passes imperceptibly into the mechanical elements of the wall of the sporangium.

We may now turn with advantage to the diagrammatic fig. I7. Here the fibrovascular tissues are shown as penetrating the stalk 
of the sporophyll. Dorsal to the strand lie transfusion elements distinguishable by their short length and reticulated walls. The tracheids of the bundles in their upward course become ever shorter, and the spiral or scalariform sculpture of the walls is gradually transformed into the reticulations which characterize the transfusion elements in which the bundle ends. The transfusion cells in turn pass by gradual transition into the mechanical elements, which are responsible for the opening of the sporangium at the time of maturity of the spores. It will be seen that the mechanical cells are not confined to the region of the sporangium wall, but pass up into the median horn, which terminates the sporophyll. In some cases the former actually more or less completely surround the secretory space at the apex. In the mature sporangium the mechanical elements extend to the sporangial cavity, being ordinarily separated from it only by a membrane formed from the disorganized tapetum. The mechanical cells form a continuous jacket, and are only interrupted in the longitudinal inner line corresponding to the stomium (not shown). The figure clearly shows that the mechanical elements are not present in the epidermis. The diagrammatic plane of section of the sporangium and sporophyll is necessarily somewhat to one side of the median line of the termination of the corresponding fibrovascular strand, since the latter continues into and is merged in transfusion elements and mechanical cells in the region of the septum between the two spore sacs. For that reason the upward end of the strand does not appear in the field of view. The explanation of the situation is furnished by reference to the horizontal section shown in fig. 3 .

It is clear from the descriptions given in the foregoing paragraphs that the fibrovascular bundles of the sporophylls in Ginkgo end in transfusion tissue, which in turn passes, often almost imperceptibly (fig. 4), into the mechanical elements of the sporangial wall. It thus is obvious that in this genus the opening mechanism of the sporangium is an adjunct if not a derivative of the fibrovascular system. This situation recalls the interesting observations made by OLIVER ${ }^{3}$ over a decade ago in the case of an isolated

3 Oliver, F. W., On a vascular sporangium from the Stephanian of Grand' Croix. New Phytol. r:60-67. pl. I. 1902. 
sporangium from the Stephanian of Grand' Croix in France. He notes that in the sporangium in question, which he is inclined to refer to the Botryopterideae, there are 6 islands of tracheary tissue lying in immediate contact with the cavity of the sporangium. A true annulus formed from the outer layer of cells likewise is present, and consequently there can be no case of vascular tissue acting as the mechanism for opening the sporangial cavity at maturity. The author notes the rarity of the phenomenon in vascular plants, where as a rule the tracheary elements stop at an interval from the actual sporogenous elements. He calls attention to the similar phenomenon presented by the tracheids found in relation to the embryo sac in the amentiferous genera Casuarina, Castanea, and Corylus. In a later article ${ }^{4}$ Oliver describes the tracheary investment covering the gametophytes and terminating in the pollen chamber of Stephanospermum akenoides and $S$. caryoides. He regards the apparatus in this case as destined to supply the pollen chamber (a constant feature of organization of more ancient gymnospermous seeds) with the water necessary to provide for the fertilizing movements of the antherozoids possessed by these extinct types in common with their nearest modern survivors Ginkgo and the Cycadales. In the living forms, however, the tracheary device for supplying fluid to the pollen chamber has disappeared. It is of interest to note in the present connection that in the megasporangium (or seed) of Ginkgo the transfusion tissue is present in the peduncle of the organ just as it is in the stalk of the microsporangium, but that it dies out sharply as the megasporangium proper is reached. It is present in abundance in the collar, which lies against the base of the seed. The sporangium in Ginkgo would seem, in view of the present observations, to be more tenacious of ancestral characters than is the megasporangium.

It is now desirable to consider certain general features of organization of the wall in the sporangia or microsporangia of the lower vascular plants. Fig. I3 illustrates the structure of a sporangium of Polypodium vulgare. Here the opening mechanism is provided

${ }^{4}$ Oliver, F. W., On the structure and affinities of Stephanospermum Brongniart, a genus of fossil gymnospermous seeds. Trans. Linn. Soc. London Bot. II. 6:36I-400. pls. $41-44$. I904. 
by the annulus, a derivative of the epidermal tissue. A similar situation is presented by the sporangia of other vascular cryptogams. Fig. I4 reproduces the situation for a species of Selaginella, one of the Lycopsida. In fig. I5 a microsporangium of Zamia muricata is represented. The spore sac is opened by an external annulus, precisely as in the ferns and lycopods. The epidermal character of the opening mechanism is clearly vouched for by the presence of stomata. These are visible on the upper and lower sides of the figure. Noteworthy in this case is the fact that the tracheids of the vascular bundle do not enter into the wall of the sporangium proper, but stop short at its base. Fig. I6 illustrates a surface view of the spore sac much more highly magnified, making clear the position and organization of the stomata. If we compare the condition presented by the sporangia of cycads and vascular cryptogams with that found in Ginkgo, a remarkable contrast in the character of the opening mechanism is found. In the lower forms the apparatus for the dehiscence of the spore sacs is known as an annulus and is derived from modified epidermal cells. In the case of Ginkgo, on the other hand, no annulus is present, and the opening of the sporangium is provided for by an internal mechanism, obviously an adjunct of the fibrovascular and transfusion tissues, commonly known as the mechanical layer.

It is now convenient to consider the situation in the seedbearing forms which lie above Ginkgo in the scale. The first group to be discussed in this connection is the Coniferales. One of us has pointed out in numerous recent communications that the Abietineae have the strongest claim to a primitive position among the coniferous subtribes. This view is as yet not accepted by the greater number of paleobotanists, but seems to be based on evidence which in the long run is destined to prevail. A most interesting confirmation of the hypothesis of the primitive character of the Abietineae is provided by their microsporangial resemblances to Ginkgo. In the first place, the organization of the male cone of Ginkgo is similar to that of the Abietineae, since it is composed of sporophylls each bearing two sporangia. One of us has pointed out $^{5}$ that the pollen grains of Ginkgo possess wings comparable to

5 JEFFREY, E. C., Spore conditions in hybrids and the mutation hypothesis of DeVries. Bot. Gaz. 58:322-336. pls. 22-25. I9I4. 
those of the Abietineae, and having the same relations to the similar internal structures as do those in Pinus or Abies. The possession of short shoots and the opposite pitting of the secondary wood, bars of Sanio, etc., as well as a number of other characteristics, likewise definitely indicate a closer degree of relationship between the Abietineae and the Ginkgoales than exists between the latter and any other gymnospermous group. It is accordingly of great interest and importance in the present connection to discover that in so many particulars there is the same striking agreement in the organization of the mechanical apparatus of the microsporangium in the Abietineae and the sole surviving genus Ginkgo. One of us has pointed out ${ }^{6}$ that on cogent grounds the Abietineae may be divided into two subsidiary groups, the Abieteae and the Pineae. The former are without resin canals in the secondary wood, while the latter are provided with ligneous ducts and have an organization of root, leaf, and cone in contrast to that of similar structures in the Abieteae. A further feature of distinction between the Abieteae and the Pineae is the thick wall of the sporangium in the former. The greater thickness of the wall of the microsporangium of the Abieteae makes it more favorable for study than that of the Pineae. Fig. I2 illustrates the organization of the wall of the sporangium in the genus Pseudolarix, which, on account of the absence of tanniniferous contents in the cells of the sporangium wall, is the most suitable for illustration. It is clear that the mechanical tissues in this case, as in Ginkgo, extend to the cavity of the sporangium. The outward limit of the opening mechanism in this instance is the exterior of the spore sac and not, as in Ginkgo, the layer immediately under the epidermis. The same general situation obtains in all the conifers, apparently, for throughout the group the epidermal cells have the same organization as the mechanical elements. Fig. Io reproduces a part of a vertical section of a sporangium of Pseudolarix. On the left of the figure lie certain cells which have reticulated walls. These are the transfusion elements, and further in toward the axis they are joined with the tracheids of the single fibrovascular bundle of the

${ }^{6}$ Jefrerey, E. C., The comparative anatomy of the Abietineae. Mem. Boston Soc. Nat. Hist. 6: $1-37$. pls. $1-7.1904$. 
sporophyll. Toward the right and below in the figure the typical transfusion cells pass directly into elements with a more open reticulation of the wall, the mechanical cells, which constitute the opening mechanism of the sporangium. The jacket of active cells is complete on the free surfaces of the sporangium except where the stomium is present in a terminal position. The septum between the two spore sacs is very largely composed of the fiber cells and the transfusion elements with which they are joined. Fig. I I reproduces part of a somewhat oblique vertical section of a sporophyll. Here both the sporangia appear at once; toward the right and between them lies the separating partition containing the fibrovascular strand and its associated transfusion elements. Toward the left the transfusion cells can be distinguished, passing directly into elements with much more openly reticulated walls, the mechanical cells. Fig. I8 is a somewhat diagrammatic representation of the anatomical situation in the sporangium of Pseudolarix. The tracheary strand comes into the sporophyll and passes outward, giving off a shorter or longer dorsal branch. Abaxially it spreads out into a mass of transfusion elements which are connected with the more coarsely reticulated cells, constituting the mechanical sheath of the microsporangium. Nearly opposite the point of contact of the vascular bundle with the upper wall of the sporangium lies the stomium. The sporophyll ends in a sharp upwardly directed apex, comparable to the less well developed similar structure in Ginkgo.

In the Pineae the thin wall of the pollen sac has brought with it such a degree of degeneracy that the topographical relations, seen clearly in the Abietineae, can no longer be discerned. The epidermal layer of the microsporangium is apparently in all cases fibrously thickened, and in this respect differs from the annulus found in the remaining Pteropsida. In the araucarian conifers, which are by many regarded as a primitive subtribe of the Coniferales and more nearly related to the Cordaitales than any other subtribe, significantly enough, the mechanical layer is reduced to the epidermis and has no connection whatever with the fibrovascular system. The same statement is true of the remaining subtribes of the Coniferales other than the Abietineae, which in respect 
to their sporangial mechanisms, as in so many other features, show themselves more nearly related to the Ginkgoales and consequently to the Cordaitales. In the Gnetales the opening mechanisms of the sporangia likewise are much simplified and in this respect correspond to the higher subtribes of the Coniferales.

In the highest of the seed-bearing plants, the angiosperms, the microsporangium characteristically opens through the agency of an internal fibrous layer, which has been elaborately described in the monumental memoir of CHATIN on the anatomy of the anther. In both the dicotyledons and monocotyledons this layer is, typically at least, well developed, but does not, as in the conifers, extend into the epidermis. Fig. I9 shows the organization of one of the loculaments of the anther in the common garden tulip (Tulipa Gesneriana, hybrid?). Toward the top of the figure lies the stomium, meeting with a corresponding structure belonging to the other loculament of the anther on the same side of the connective. The remainder of the wall shows the mechanical layer strongly developed. In the epidermis stomata can be distinguished. Clearly there is no relation between the mechanical layer and the fibrovascular layer in the connective.

Turning our attention now to the dicotyledons, in fig. 20 we find a diagrammatic representation of a loculament of the anther of Diervilla florida, the bush honeysuckle. The stomium does not appear in the figure, but the mechanical or fibrous layer of the anther is clearly to be seen, and, like that in the tulip, it does not extend into the epidermis. In this case, as in the other angiospermous sporangium figured, there is no connection between the mechanical tissues and the fibrovascular bundle of the microsporophyll. On account of the unique development of transfusion tissue of a gymnospermous character in the genus Casuarina, it seemed possible that there might be here, if anywhere, some connection between the mechanical tissues of the microsporangium and the fibrovascular bundles. Investigation of the stamens of two species of the genus, however, revealed the same general situation as is found in other instances among the angiosperms; namely, the absence of a relation of continuity between the reticulated cells of the sporangial mechanism and the fibrovascular 
strand. It is to be noted that the megasporangial tracheids described by Treub and Benson in Casuarina, Castanea, Corylus, etc., are equally without any relation of continuity with the bundle system of the ovule. In general, in the angiosperms the opening of the cavities of the anther takes place by means of a mechanical device, which is not of epidermal origin, and consequently cannot be regarded as an annulus. The structure in question has clearly originated in the deeper tissues of the sporangial wall, and is in all probability derived from the fibrovascular system, as are similar devices in Ginkgo and the Abietineae. In the highest seed plants all relation between the opening mechanisms of the anther and the fibrovascular structures have apparently long disappeared.

It is obvious from the discussion of the pertusing devices of sporangia in the preceding pages that there are two main types of opening mechanisms; namely, the annulus, which is clearly of epidermal origin (in the Cycadales actually containing stomata), and, secondly, the fiber layer, occurring in a more or less complete condition from the Ginkgoales upward. This seems equally clearly to have been derived from the fibrovascular structures. Those sporangia which are opened by the instrumentality of an annulus may be appropriately designated ectokinetic, while those which owe their dehiscence to the stresses originated by an internal mechanical system, derived from the fibrovascular tissues, may with equal fitness be termed endokinetic. If these distinctions be well founded, they obviously supply us with a valuable additional criterion for the course of evolution in the higher plants. The application of these criteria makes it apparently clear that the angiosperms cannot have been derived from the Cycadophyta, a phylogeny which, moreover, meets many other anatomical difficulties and cannot even be easily reconciled with a reasonable interpretation of the external features of the reproductive parts of the bennettitalean Cycadales and the ranalian angiosperms.

\section{Summary}

I. In Ginkgo the opening mechanism is clearly an adjunct of the transfusion tissue of the fibrovascular system and is directly continuous with this. 
2. A similar condition of relationship between the tracheary tissues and the dehiscing mechanism of the microsporangium is likewise found in the Abietineae among the conifers.

3. In the remaining conifers (and including the araucarians) the sporangial mechanisms are much reduced and no longer have a relation to the vascular bundles of the sporophyll.

4. In the angiosperms the fiber layer of the anther wall is usually well developed and is of internal origin, but has no connection with the fibrovascular system, even in the forms regarded as low.

5. From the Cycadales downward the opening mechanism of the sporangium is of the nature of an annulus and is epidermal in its origin.

6. The facts summarized under the foregoing headings justify the separation of reproductive mechanisms in the vascular plants into two types, the ectokinetic and endokinetic. The former condition is represented by the annulus and is characteristic of lower forms; the latter is found in the fiber layer, derived from the fibrovascular tissues (particularly modified transfusion elements), and is present characteristically in the microsporangia of existing seed plants (exclusive of the Cycadales).

HARVARD UNIVERSITY

\section{EXPLANATION OF PLATES VII-IX}

PLATE VII

FIG. I.-Vertical section through upper part of sporophyll of Ginkgo biloba, showing relation of mechanical elements of wall of sporangium to transfusion cells and fibrovascular bundle; $\times$ roo.

FIG. 2.-Vertical section of anothersporangium showing the same features; $\times 150$.

FIG. 3.-Horizontal section showing relation of two fibrovascular bundles to transfusion tissue and mechanical elements; $\times$ roo.

FIg. 4.-Part of the right of fig. 3 more highly magnified, showing merging of transfusion elements into mechanical elements; $X_{200}$.

FIG. 5.-Vertical section of sporangium of Ginkgo, showing termination of bundle in transfusion elements and mechanical cells; $X_{150}$.

Fig. 6.-Vertical section of sporangium of Ginkgo, showing termination of bundle in transfusion elements and mechanical cells; $\times 250$. 
FIg. 7.-Vertical section of sporangium of Ginkgo, showing termination of bundle in transfusion cells and mechanical elements; $\times 25^{\circ}$.

FIg. 8.-Transverse section of sporophyll of Ginkgo, showing 2 fibrovascular bundles; $\times$ r 50 .

FIG. 9.-Oblique section of sporophyll of Ginkgo, showing on the left transition of bundle into mechanical cells; $\times 200$.

FIG. ro.-Vertical section of sporangium of Pseudolarix, showing transition of bundle into transfusion tissue and mechanical cells; $\times 200$.

FIg. Ir.-Vertical section of sporophyll of Pseudolarix, showing termination of transfusion tissue in mechanical elements of the walls of the sporangium; $\times 200$.

FIG. 12.-Section of sporangium of Pseudolarix, showing wall consisting of mechanical cells; $\times 200$.

\section{PLATE IX}

FIG. 13.-Sporangium of Polypodium vulgare as illustration of sporangial mechanism in a typical fern.

FIG. I4.-Diagrammatic representation of opening mechanism of sporangium of Selaginella.

FIG. 15.-Semi-diagrammatic view of sporangium in Zamia.

FIG. 16.- Surface view of sporangium in Zamia showing stomata enlarged.

FIG. 17.-Semi-diagrammatic view of one of the sporangia of Ginkgo, showing relation of fibrovascular tissues to opening mechanism of the sporangium.

FIG. I8.-Semi-diagrammatic illustration of organization of the sporangium in Pseudolarix, showing relation of fibrovascular tissues to opening mechanism of sporangium.

FIG. rg.-Transverse section of sporangium of tulip, showing mechanical cells.

FIG. 20.-Transverse section of sporangium of Diervilla, showing sporangial mechanism. 

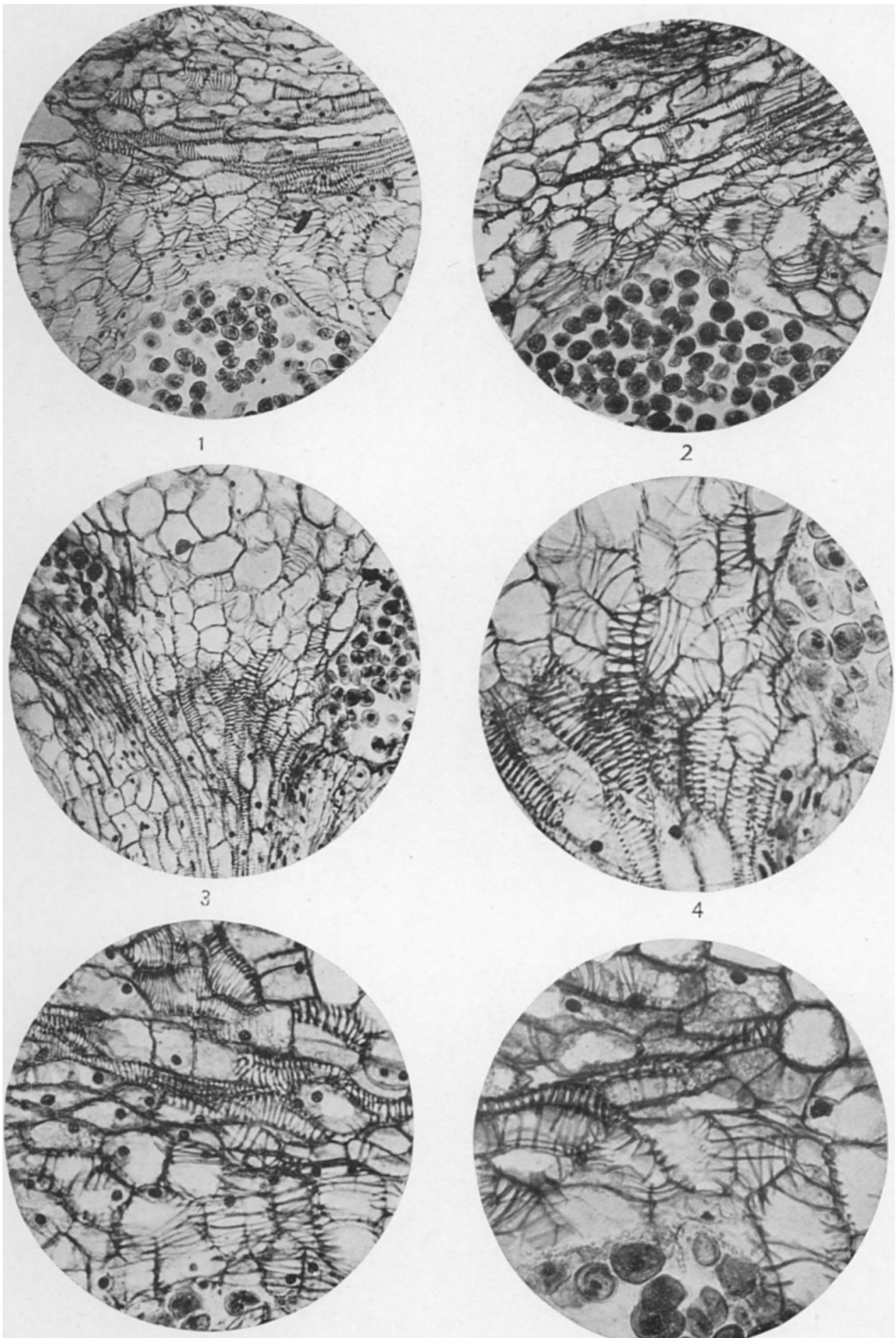

5

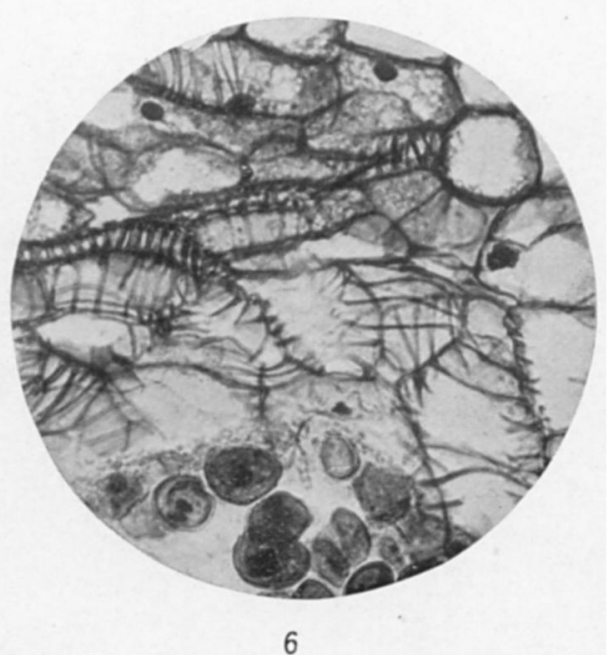

JEFFREY and TORREY on GINKGO

This content downloaded from 080.082.077.083 on February 19, 2018 18:59:01 PM

All use subject to University of Chicago Press Terms and Conditions (http://www.journals.uchicago.edu/t-and-c). 

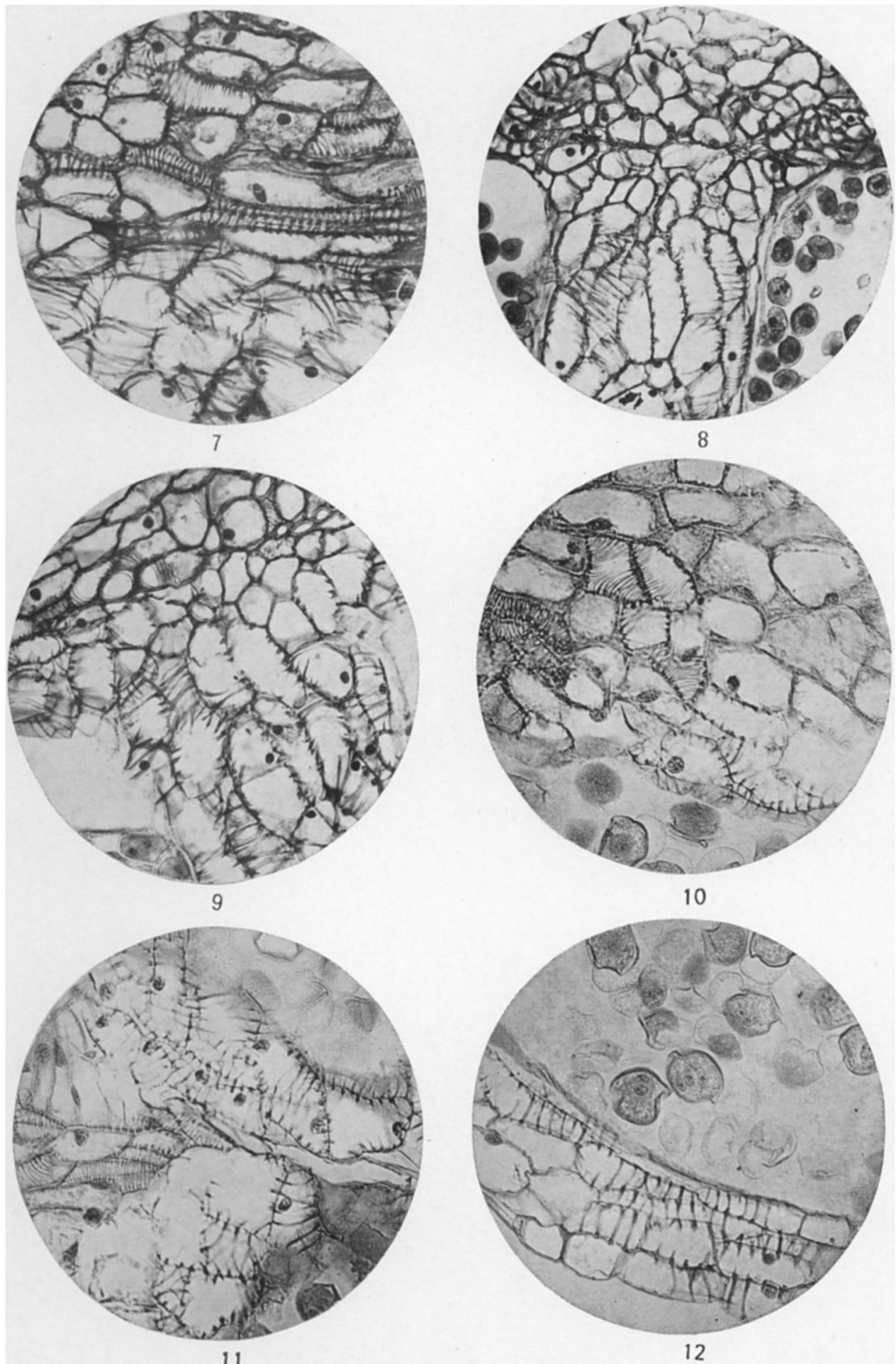

11

JEFFREY and TORREY on GINKGO 

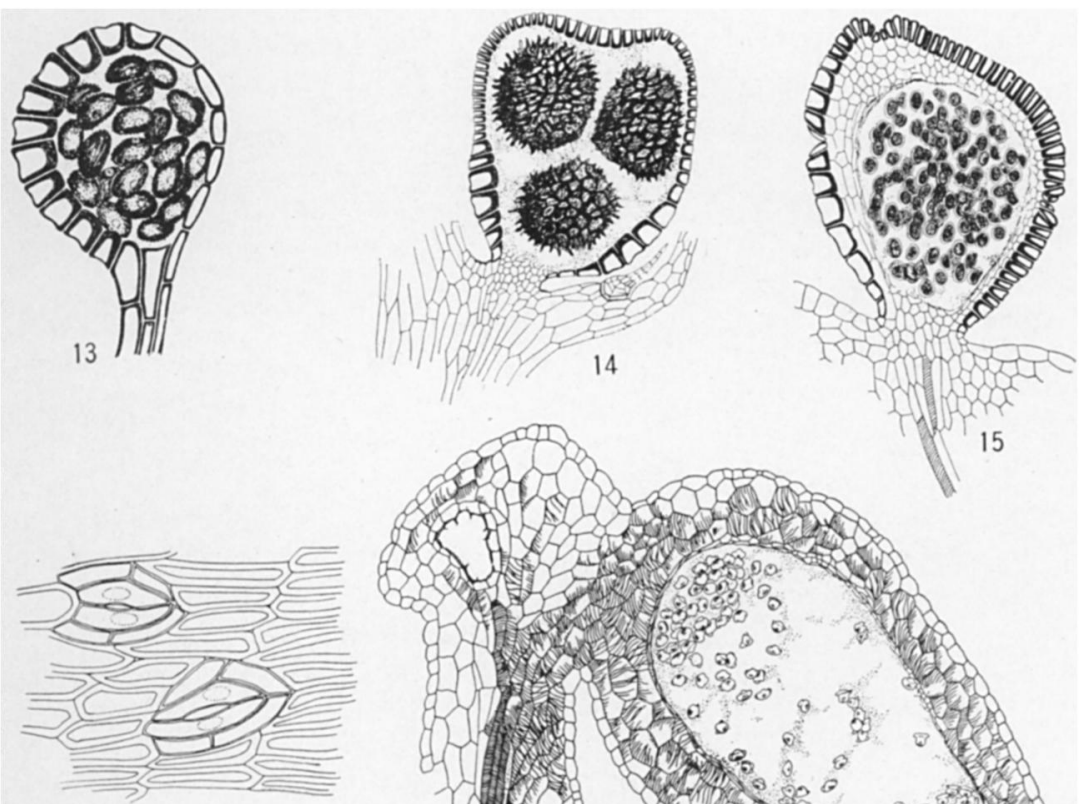

16
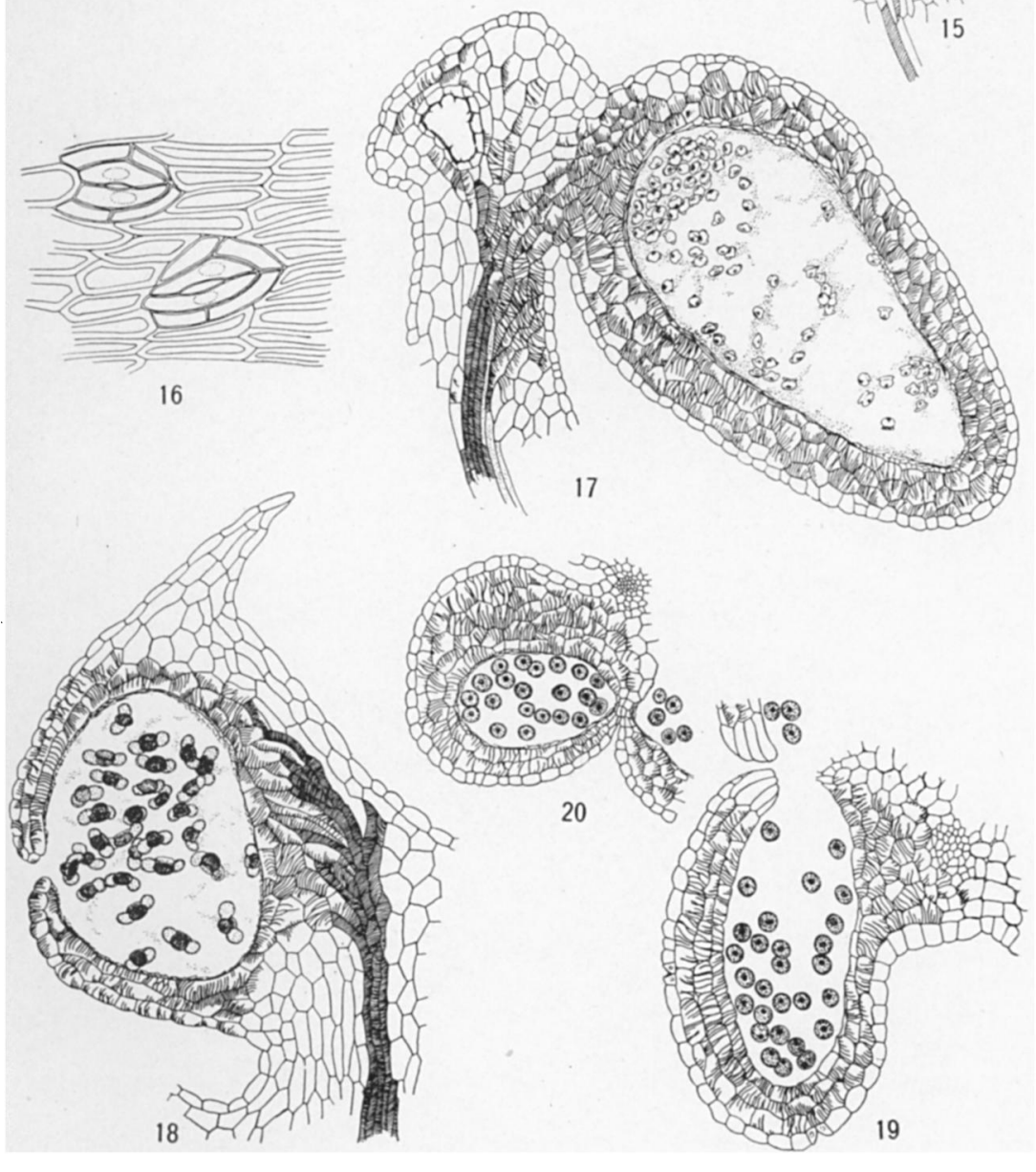

JEFFREY and TORREY on GINKGO

This content downloaded from 080.082.077.083 on February 19, 2018 18:59:01 PM All use subject to University of Chicago Press Terms and Conditions (http://www.journals.uchicago.edu/t-and- 